\title{
Modelling and Analysis of an Aircraft On-board Electric Taxiing System
}

\author{
Milos Lukic ${ }^{1}$, Paolo Giangrande ${ }^{1}$, Christian Klumpner ${ }^{1}$, Michael Galea ${ }^{1,2}$ \\ ${ }^{1}$ PEMC, University of Nottingham, United Kingdom \\ ${ }^{2}$ School of Aerospace, University of Nottingham Ningbo China, PRC \\ Email: Milos.Lukic@nottingham.ac.uk
}

\begin{abstract}
This paper presents a model that enables analysis and design validation of an aircraft on-board electric taxiing system. A detailed model, which includes power electronics, electrical machine and mechanical drivetrain, is first developed and discussed. The model is then employed for simulating two characteristic taxiing mission profiles with a Boeing 737-400 as a selected benchmark aircraft. From the simulation findings, acceleration performance, power and energy load profiles, as well as the energy harvesting stages are studied. These outcomes allow to evaluate the appropriate energy storage technology to be selected, enabling complete emission free aircraft taxiing.
\end{abstract}

Keywords-Electric taxiing, modelling, double star PMSM

\section{INTRODUCTION}

In light of the general push towards the electrification of aircraft [1], several electrically-assisted taxiing concepts have been recently proposed and developed. Namely, taxiing is the phase of flight in which the movement of an aircraft under its own power occurs on the surface of an aerodrome, excluding take-off and landing [2]. Thus, nowadays taxiing is performed by the means of main engines, during which they are set to idle thrust of $7 \%$. Considering their inefficiency in that thrust range, along with the long taxiing time due to the ever-increasing congestion of the airports, a significant amount of fuel is burned during taxiing phase raising both economic and environmental concerns. For instance, every year 17 million of tones of $\mathrm{CO}_{2}$ is emitted during taxiing phase. Moreover, pushback of an aircraft is currently performed by assisted tug vehicles, which decreases its autonomy and increases overall taxiing time [3].

Thus, it is not surprising that taxiing phase has been targeted for the major improvements in order to comply with the future regulations, such as FlightPath 2050 [4]. Among the many proposed operational and technological solutions to mitigate the aforementioned issues [5], the most interesting ones are based on electrically-assisted taxiing concept, also called electric taxiing (ET) systems. In particular, the onboard ET solutions, in which electric traction motors (TMs) are embedded in the wheels of either main landing gear (MLG) or nose landing gear (NLG), recently have acquired high interest due to their advantages over conventional taxiing.

Since during ET main engines are turned off, it is expected that ET system implementation will lead to better fuel utilization. Indeed, studies showed that the implementation of on-board ET systems can cut the total fuel consumption by $4 \%$ and simultaneously reduce emissions on average by $40 \%$ compared to the conventional taxiing [6][7]. This concept not only enhances the fuel savings, but also provides the opportunity of installing a local energy storage device (LESD) that can be used for recovering braking energy during the taxiing operation. In addition, it has also been acknowledged that employing LESD, such as batteries

This work is funded by the INNOVATIVE doctoral programme. The INNOVATIVE programme is partially funded by the Marie Curie Initial Training Networks (ITN) action (project number 665468) and partially by the Institute for Aerospace Technology (IAT) at the University of Nottingham. and fuel cells, can enable the complete emission free taxiing [8].

In this paper, an on-board ET system is modelled and investigated in detail. The model developed in PLECS ${ }^{\circledR}$ environment is adopted for assessing the ET system behavior under several taxiing mission profiles. Hence, regeneration capabilities and acceleration performance are investigated as well as the required power and energy levels.

\section{DESCRIPTION OF THE ET SYSTEM}

The ET system investigated in this paper is integrated into two MLGs of a mid-size commercial aircraft, such as Boeing B737 and Airbus A320. Since each MLG features two wheels, a maximum of four motors can be installed in this configuration type. However, only one TM is mounted per MLG, giving in total $\mathrm{n}_{\mathrm{m}}=2$ mounted TMs. Furthermore, a direct-drive configuration is addressed [9], where the TMs are connected directly to the wheel, without any gearboxes and clutch mechanisms. This architecture reveals advantages as higher mechanical reliability and lower maintenance cost [10][11]. On the other hand, the design of the TM is more challenging, since the motor should be able to deliver high traction torque to the wheel, without the gearbox aid and within limited space. Design process and constraints of the chosen motor are presented in [10], [12]. The developed TM is a 36 slot/42 pole, 2x3-phase synchronous permanent magnet (PMSM) machine, fed by two 3-phase voltage source inverters (VSI) connected to the same DC link of $540 \mathrm{~V}$, as shown in Fig. 1.

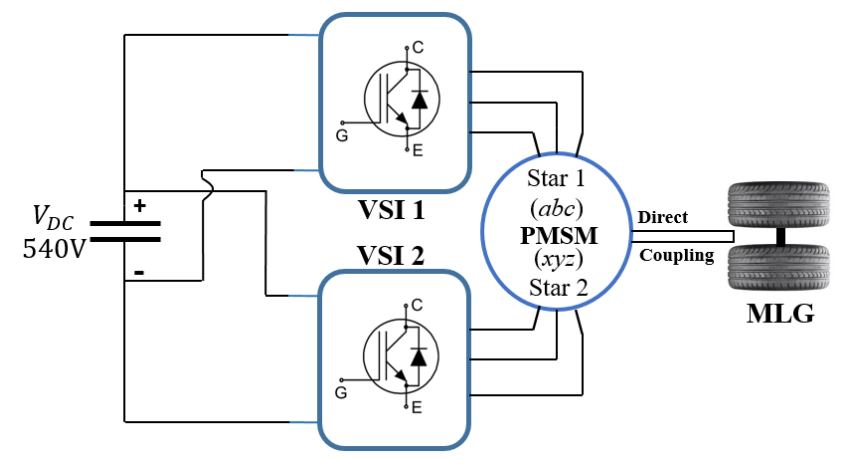

Fig. 1. ET drive unit of one MLG.

In order to enhance the TM power density, the following features have been applied: 1.) outer rotor configuration, 2.) 5 stage Halbach array configuration 3.) Double layer fractional slot concentrated windings (FSCW). The 2D finite element (FE) model of the machine was developed in order to assess its performance and calculate its parameters. The cross section of one part of the FE model is reported in Fig. 2.

Machine's behavior (no-load and load operation) and its parameters such as stator winding inductance and resistance matrices were obtained through the set of transient with 


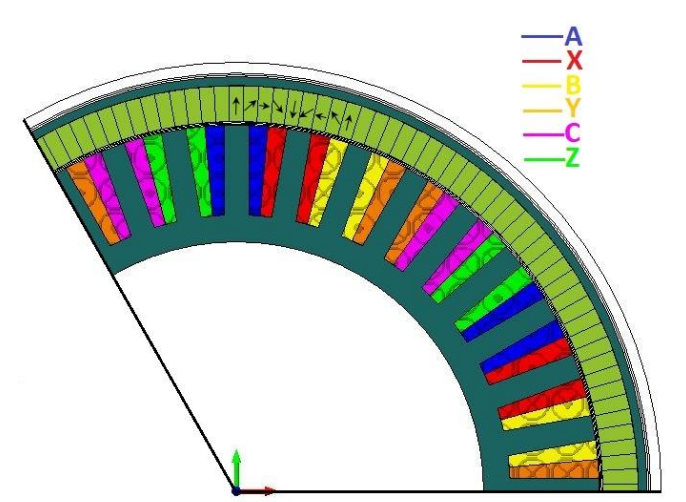

Fig. 2.Part of the cross section of 2D FE element model of TM. motion and static FE simulations. For instance, in Fig. 3 no-load flux linkages are shown at $120 \mathrm{rpm}$, and the PM flux is equal to $\Psi_{\mathrm{pm}}=0.654 \mathrm{~Wb}$ (peak value). Also torque production was investigated. At full load condition, i.e. both stars fed with $223 \mathrm{~A}$ along the $q$-axis, the maximum produced torque corresponds to $7 \mathrm{kNm}$.

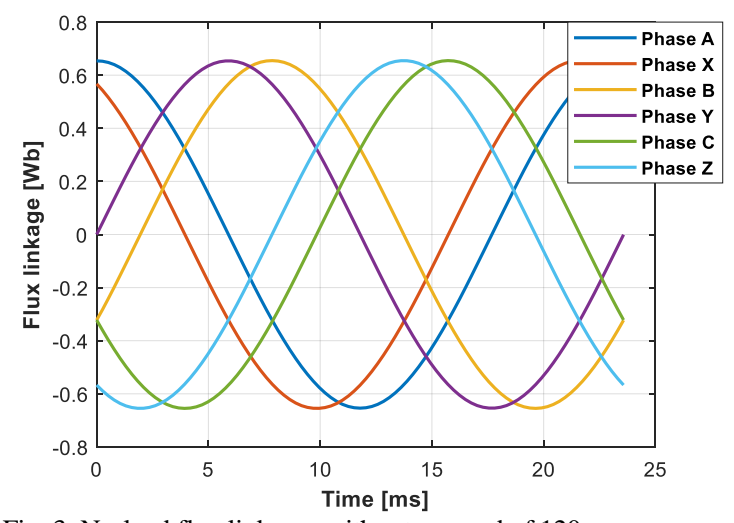

Fig. 3. No-load flux linkages with rotor speed of $120 \mathrm{rpm}$.

The stator resistance matrix $\mathrm{R}$ is a diagonal matrix, $\operatorname{diag}\left(R_{s}\right)_{6 \times 6}$, with $R_{s}=0.154 \Omega$, while the inductance matrix is defined as in (1), where the mutual coupling terms between the two winding stars are highlighted.

$$
\mathbf{L}=\left[\begin{array}{ll}
\mathbf{L}_{\mathrm{s} 1, \mathrm{abc}} & \mathbf{M}_{\mathrm{s} 1, \mathrm{~s} 2} \\
\mathbf{M}_{\mathrm{s} 2, \mathrm{~s} 1} & \mathbf{L}_{\mathrm{s} 2, \mathrm{xyz}}
\end{array}\right]_{6 \mathrm{x} 6}
$$

In particular, $\mathbf{L}_{\mathrm{s} 1 \text {,abc }}$ and $\mathbf{L}_{\mathrm{s} 2 \text {,xyz }}$ represent magnetic coupling between phases belonging to the same star and they are given by (2) and (3) respectively, whilst $\mathbf{M}_{\mathrm{s} 1, \mathrm{~s} 2}$ and $\mathbf{M}_{\mathrm{s} 2, \mathrm{~s} 1}$ account for the coupling between phases of different stars and their expression in provided in (4) and (5) respectively.

$$
\begin{gathered}
\mathbf{L}_{\mathrm{abc}, \mathrm{s} 1}=\left[\begin{array}{lll}
\mathrm{L}_{\mathrm{aa}} & \mathrm{L}_{\mathrm{ab}} & \mathrm{L}_{\mathrm{ac}} \\
\mathrm{L}_{\mathrm{ba}} & \mathrm{L}_{\mathrm{bb}} & \mathrm{L}_{\mathrm{bc}} \\
\mathrm{L}_{\mathrm{ca}} & \mathrm{L}_{\mathrm{cb}} & \mathrm{L}_{\mathrm{cc}}
\end{array}\right]=\left[L_{i j}\right] i, j \in S_{1}=\{a, b, c\}(2) \\
\mathbf{L}_{\mathrm{xyz}, \mathrm{s} 2}=\left[L_{i j}\right] i, j \in S_{2}=\{x, y, z\} \\
\mathbf{M}_{\mathrm{s} 1, \mathrm{~s} 2}=\left[M_{i j}\right] i \in S_{1}, j \in S_{2} \\
\mathbf{M}_{\mathrm{s} 2, \mathrm{~s} 1}=\left[M_{i j}\right] i \in S_{2}, j \in S_{1}
\end{gathered}
$$

Each element of the above-mentioned matrices was evaluated and calculated separately. Simulations showed that $\mathbf{L}$ matrices are diagonal (6), while $\mathbf{M}$ matrices feature the topology in (7), where $\mathrm{L}_{\mathrm{s}}=3.95 \mathrm{mH}$ and $\mathrm{M}_{\mathrm{s}}=1.031 \mathrm{mH}$.

$$
\begin{gathered}
\mathbf{L}_{\mathrm{abc}, \mathrm{s} 1}=\mathbf{L}_{\mathrm{xyz}, \mathrm{s} 2}=\left[\begin{array}{ccc}
\mathrm{L}_{\mathrm{s}} & 0 & 0 \\
0 & \mathrm{~L}_{\mathrm{s}} & 0 \\
0 & 0 & \mathrm{~L}_{\mathrm{s}}
\end{array}\right] \\
\mathbf{M}_{\mathrm{s} 1, \mathrm{~s} 2}=\mathbf{M}_{\mathrm{s} 2, \mathrm{~s} 1}^{\mathrm{T}}=\left[\begin{array}{ccc}
\mathrm{M}_{\mathrm{s}} & 0 & -\mathrm{M}_{\mathrm{s}} \\
-\mathrm{M}_{\mathrm{s}} & \mathrm{M}_{\mathrm{s}} & 0 \\
0 & -\mathrm{M}_{\mathrm{s}} & \mathrm{M}_{\mathrm{s}}
\end{array}\right]
\end{gathered}
$$

The former matrix structure (i.e. L) indicates that there is no coupling between phases of the same star, which is expected since windings are double layer FSCW. Furthermore, the mutual coupling between stars is also reduced, since only phases placed in neighbouring slots reveals appreciable magnetic coupling.

In the $a b c(x y z)$ domain, the TM can mathematically be described using (8) and (9)

$$
\begin{gathered}
\mathbf{v}=\mathbf{R i}+\frac{\mathrm{d} \boldsymbol{\psi}}{\mathrm{dt}} \\
\boldsymbol{\psi}=\mathbf{L i}+\boldsymbol{\psi}_{\mathrm{pm}}
\end{gathered}
$$

where $\mathbf{v}, \mathbf{i}, \boldsymbol{\psi}$ and $\boldsymbol{\psi}_{\mathrm{pm}}$ are vectors of form $\left[\mathrm{f}_{\mathrm{abc}} \mathrm{f}_{\mathrm{xyz}}\right]^{\mathrm{T}}=\left[\mathrm{f}_{\mathrm{a}}\right.$ $\left.\mathrm{f}_{\mathrm{b}} \mathrm{f}_{\mathrm{c}} \mathrm{f}_{\mathrm{x}} \mathrm{f}_{\mathrm{y}} \mathrm{f}_{\mathrm{z}}\right]^{\mathrm{T}}$. However, as in any electric drive application, conventional $a b c$ frame models are not practical, so the TM is modelled in the $d q$ rotating reference frame. In the following section, models of the machine, inverters and aircraft dynamics are presented.

\section{MODELLING OF THE ET SYSTEM}

Two main modelling approaches that are applied for modelling of electric drives used in traction applications are: 1.) backward and 2.) forward-facing methods, depending on the desired direction of the calculation [13]. Input to the model in both approaches is the same, i.e. the reference speed of the mission profile. However, using the backward-facing method, power required at the wheels is first calculated using vehicle model and accordingly the power from the source is determined "'going backwards" through each model component [14]. Contrary to the backward-facing method, in the forward-facing models it is not assumed that vehicle's speed is equal to the drive cycle's speed at every time instant. As a matter of fact, a speed drive cycle is fed to the driver block that outputs correct torque demand necessary for the vehicle to meet that speed. According to that torque demand, controller outputs a reference modulation signals that are applied to the inverter that supplies TM, in order to generate desired torque as shown in Fig. 4. Forward facing-methods naturally represent dynamic models with correct causality, whereas backward-facing methods represent quasi-static models [14].

Another important modelling aspect is the level of complexity of each model component. The more complex the model, the more details and phenomena can be observed. On the other hand, very detailed models, such as switching models of power converters, are difficult to simulate over long duty cycles, due to the computational burden. If the model has to be simulated over long period, averaged models can represent accurately large signal transients without high frequency computational load [15].

Thus, ET system of Fig. 1 is modelled using forwardfacing method that implements dynamic averaged models of the TM, VSI and aircraft dynamics. This approach allows to evaluate energy and power requirements of the ET system, and more importantly it allows, in later stage, to easily connect dynamic models of various LESDs to the already developed ET system model and analyse their impact on it. 


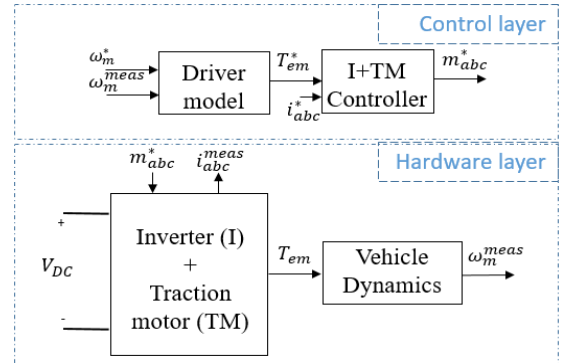

Fig. 4. Forward-facing modelling approach.

\section{A. $d q$ Model of 6-phase PMSM}

Numerous 6-phase machine modelling methods exist, but the two most prevalent ones are vector space decomposition (VSD) and two-individual three-phase method [16]. The latter one assumes modelling in $d q$ frame and it is more favourable if the machine is powered from two separate inverters [17], thus this modelling approach has been selected in this paper. The modelling process slightly differs from the standard procedure as for conventional 3-phase machines, due to the additional phase coupling induced by the second set of 3 -phase winding. Nonetheless, all rotating vectors are projected to the unique $d q$ reference frame with $d$-axis aligned with the vector of PM flux linkage, where angle $\theta$ is measured from the $a$ magnetic axis to the $q$ axis as in [18] (Fig. 5). Matrix $\mathbf{K}(\theta)$, which transforms $a b c$ to $d q$ variables, is defined in (10), whereas the transformation matrix associated to the variables of winding $x y z$ is $\mathrm{K}(\theta+30)$. Transformation equations are presented in (11) and (12), where $\mathbf{f}_{\mathrm{qd} 0}=\left[\mathrm{f}_{\mathrm{q}} \mathrm{f}_{\mathrm{d}} \mathrm{f}_{0}\right]^{\mathrm{T}}$ represents either current, voltage or flux linkage values in rotating reference frame and the subscripts s1 and s2 stand for the winding sets $a b c$ and $x y z$ respectively.

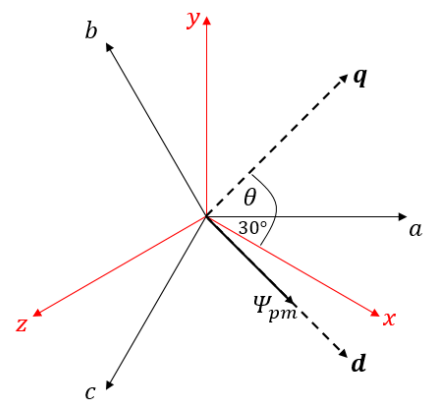

Fig. 5. $d q$ reference frame definition.

$$
\begin{gathered}
\mathbf{K}(\theta)=\frac{2}{3}\left[\begin{array}{ccc}
\cos (\theta) & \cos \left(\theta-\frac{2 \pi}{3}\right) & \cos \left(\theta+\frac{2 \pi}{3}\right) \\
\sin (\theta) & \sin \left(\theta-\frac{2 \pi}{3}\right) & \sin \left(\theta+\frac{2 \pi}{3}\right) \\
\frac{1}{2} & \frac{1}{2} & \frac{1}{2}
\end{array}\right] \\
\mathbf{f}_{\mathrm{qd} 0, \mathrm{~s} 1}=\mathbf{K}(\theta) \mathbf{f}_{\mathrm{abc}}, \mathbf{f}_{\mathrm{abc}}=\mathbf{K}^{-\mathbf{1}}(\theta) \mathbf{f}_{\mathrm{qd} 0, \mathrm{~s} 1} \\
\mathbf{f}_{\mathrm{qd} 0, \mathrm{~s} 2}=\mathbf{K}(\theta+30) \mathbf{f}_{\mathrm{xyz}}, \mathbf{f}_{\mathrm{xyz}}=\mathbf{K}^{-\mathbf{1}}(\theta+30) \mathbf{f}_{\mathrm{qd} 0, \mathrm{~s} 2}
\end{gathered}
$$

Transformation equations (11) and (12) can be written as in (13) and (14) respectively.

$$
\begin{array}{r}
{\left[\begin{array}{l}
\mathbf{f}_{\mathrm{qd} 0, \mathrm{~s} 1} \\
\mathbf{f}_{\mathrm{qd} 0, \mathrm{~s} 2}
\end{array}\right]=\left[\begin{array}{cc}
\mathbf{K}(\theta) & \mathbf{O}_{3 \mathrm{x} 3} \\
\mathbf{O}_{3 \mathrm{x} 3} & \mathbf{K}(\theta+30)
\end{array}\right]\left[\begin{array}{l}
\mathbf{f}_{\mathrm{abc}} \\
\mathbf{f}_{\mathrm{xyz}}
\end{array}\right]=\underline{=}=\left[\begin{array}{l}
\mathbf{f}_{\mathrm{abc}} \\
\mathbf{f}_{\mathrm{xyz}}
\end{array}\right]} \\
{\left[\begin{array}{c}
\mathbf{f}_{\mathrm{abc}} \\
\mathbf{f}_{\mathrm{xyz}}
\end{array}\right]=\left[\begin{array}{cc}
\mathbf{K}^{-1}(\theta) & \mathbf{O}_{3 \mathrm{x} 3} \\
\mathbf{O}_{3 \mathrm{x} 3} & \mathbf{K}^{-\mathbf{1}}(\theta+30)
\end{array}\right]\left[\begin{array}{l}
\mathbf{f}_{\mathrm{qd} 0, \mathrm{~s} 1} \\
\mathbf{f}_{\mathrm{qd} 0, \mathrm{~s} 2}
\end{array}\right]=\mathbf{K}^{\mathbf{- 1}}\left[\begin{array}{l}
\mathbf{f}_{\mathrm{qd} 0, \mathrm{~s} 1} \\
\mathbf{f}_{\mathrm{qd} 0, \mathrm{~s} 2}
\end{array}\right]}
\end{array}
$$

By applying transformations $\underline{\underline{\mathbf{K}}}$ and $\underline{\underline{\mathbf{K}}}^{-1}$ to the voltage equation (8), the 3-phase voltages of both winding sets are referred in the $d q$ frame as

$$
\begin{aligned}
& \mathbf{v}_{\mathrm{qd} 0, \mathrm{~s} 1}=\mathbf{R}_{\mathrm{qd} 0, \mathrm{~s} 1} \mathbf{i}_{\mathrm{qd} 0, \mathrm{~s} 1}+\frac{\mathrm{d} \boldsymbol{\psi}_{\mathrm{qd} 0, \mathrm{~s} 1}}{\mathrm{dt}}+\omega\left[\begin{array}{c}
\psi_{\mathrm{d}, \mathrm{s} 1} \\
-\psi_{\mathrm{q}, \mathrm{s} 1} \\
0
\end{array}\right] \\
& \mathbf{v}_{\mathrm{qd} 0, \mathrm{~s} 2}=\mathbf{R}_{\mathrm{qd} 0, \mathrm{~s} 2} \mathbf{i}_{\mathrm{qd} 0, \mathrm{~s} 2}+\frac{\mathrm{d} \psi_{\mathrm{qd} 0, \mathrm{~s} 2}}{\mathrm{dt}}+\omega\left[\begin{array}{c}
\psi_{\mathrm{d}, \mathrm{s} 2} \\
-\psi_{\mathrm{q}, \mathrm{s} 2} \\
0
\end{array}\right]
\end{aligned}
$$

where $\omega$ is the machine's electrical speed. As a last step, also the flux equation (9) is expressed in the $d q$ frame. Applying transformations $\underline{\underline{\mathbf{K}}}$ and $\underline{\mathbf{K}}^{-1}$ to (9) yields (17)

$$
\left[\begin{array}{l}
\boldsymbol{\Psi}_{\mathrm{qd} 0, \mathrm{~s} 1} \\
\boldsymbol{\Psi}_{\mathrm{qd} 0, \mathrm{~s} 2}
\end{array}\right]=\left[\begin{array}{cc}
\mathbf{L}_{\mathrm{qd}, \mathrm{s} 1} & \mathbf{M}_{\mathrm{qd}, 12} \\
\mathbf{M}_{\mathrm{qd}, 21} & \mathbf{L}_{\mathrm{qd}, \mathrm{s} 2}
\end{array}\right]\left[\begin{array}{c}
\mathbf{i}_{\mathrm{qd} 0, \mathrm{~s} 1} \\
\mathbf{i}_{\mathrm{qd} 0, \mathrm{~s} 2}
\end{array}\right]+\left[\begin{array}{c}
\boldsymbol{\Psi}_{\mathrm{pm}, \mathrm{qd} 0, \mathrm{~s} 1} \\
\boldsymbol{\Psi}_{\mathrm{pm}, \mathrm{qd} 0, \mathrm{~s} 2}
\end{array}\right](17)
$$

in which

$$
\begin{gathered}
\boldsymbol{\Psi}_{\mathrm{pm}, \mathrm{qd} 0, \mathrm{~s} 1}=\boldsymbol{\Psi}_{\mathrm{pm}, \mathrm{qd} 0, \mathrm{~s} 2}=\left[\begin{array}{c}
0 \\
\Psi_{\mathrm{pm}} \\
0
\end{array}\right] \\
{\left[\begin{array}{cc}
\mathbf{L}_{\mathrm{qd}, \mathrm{s} 1} & \mathbf{M}_{\mathrm{qd}, 12} \\
\mathbf{M}_{\mathrm{qd}, 21} & \mathbf{L}_{\mathrm{qd}, \mathrm{s} 2}
\end{array}\right]=\underline{\mathbf{K}}\left[\begin{array}{ll}
\mathbf{L}_{\mathrm{abc}, \mathrm{s} 1} & \mathbf{M}_{\mathrm{s} 1, \mathrm{~s} 2} \\
\mathbf{M}_{\mathrm{s} 2, \mathrm{~s} 1} & \mathbf{L}_{\mathrm{xyz}, \mathrm{s} 2}
\end{array}\right] \underline{\mathbf{K}}^{-\mathbf{1}}}
\end{gathered}
$$

By expanding previous equation, $\mathbf{L}$ and $\mathbf{M}$ matrices in $d q$ frame are obtained as

$$
\begin{aligned}
& \mathbf{L}_{\mathbf{q d}, \mathbf{s} 1}=\mathbf{K}(\theta) \mathbf{L}_{\mathrm{abc}, \mathrm{s} 1} \mathbf{K}^{-\mathbf{1}}(\theta)=\left[\begin{array}{ccc}
\mathrm{L}_{\mathrm{q}} & 0 & 0 \\
0 & \mathrm{~L}_{\mathrm{d}} & 0 \\
0 & 0 & \mathrm{~L}_{0}
\end{array}\right]=\mathbf{L}_{\mathrm{qd}, \mathrm{s} 2} \\
& \mathbf{M}_{\mathrm{qd}, 12}=\mathbf{K}(\theta) \mathbf{M}_{\mathrm{s} 1, \mathrm{~s} 2} \mathbf{K}^{-1}(\theta+30)=\left[\begin{array}{ccc}
\mathrm{M}_{\mathrm{q}} & 0 & 0 \\
0 & \mathrm{M}_{\mathrm{d}} & 0 \\
0 & 0 & \mathrm{M}_{0}
\end{array}\right]
\end{aligned}
$$

where $\mathrm{L}_{\mathrm{q}}=\mathrm{L}_{\mathrm{d}}=\mathrm{L}=3.95 \mathrm{mH}$ and $\mathrm{M}_{\mathrm{q}}=\mathrm{M}_{\mathrm{d}}=\mathrm{M}=1.7857 \mathrm{mH}$. Thus, the electrical model of the machine is represented in Fig. 6 and 7 in the form of electric circuits.

In order to complete the TM model, mechanical equation should be included, i.e. electromagnetic torque should be calculated. The TM overall torque can be seen as the sum of the two torques, each developed by every winding set.

$$
\begin{gathered}
\mathrm{T}_{\mathrm{em}}=\mathrm{T}_{\mathrm{em}, \mathrm{s} 1}+\mathrm{T}_{\mathrm{em}, \mathrm{s} 2} \\
\mathrm{~T}_{\mathrm{em}}=\frac{3}{2} \mathrm{p}\left(\psi_{\mathrm{d}, \mathrm{s} 1} \mathrm{i}_{\mathrm{q}, \mathrm{s} 1}-\psi_{\mathrm{q}, \mathrm{s} 1} \mathrm{i}_{\mathrm{d}, \mathrm{s} 1}+\psi_{\mathrm{d}, \mathrm{s} 2} \mathrm{i}_{\mathrm{q}, \mathrm{s} 2}-\psi_{\mathrm{q}, \mathrm{s} 2} \mathrm{i}_{\mathrm{d}, \mathrm{s} 2}\right)
\end{gathered}
$$

Since machine is non-salient and $\mathrm{M}_{\mathrm{q}}=\mathrm{M}_{\mathrm{d}}$, torque is only dependent on $\mathrm{i}_{\mathrm{q}}$ currents.

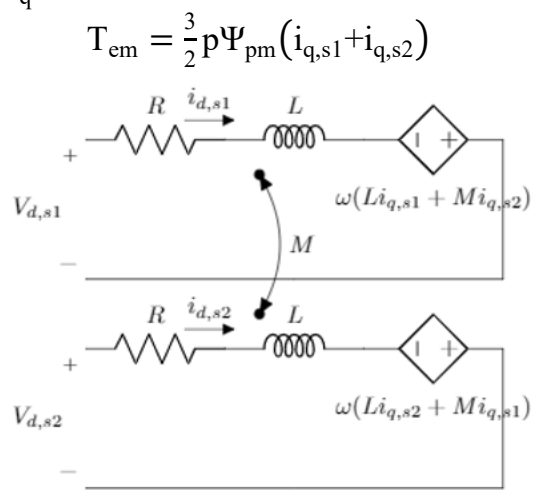

Fig. 6. $d$ equivalent circuits of 2x3-phase PMSM. 


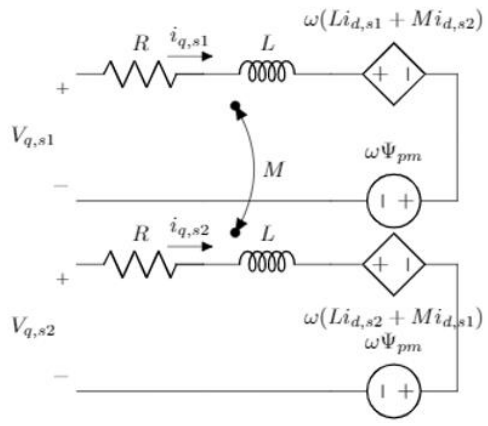

Fig. 7. $q$ equivalent circuits of $2 \times 3$-phase PMSM.

\section{B. Averaged dq Model of VSIs}

Typical configuration of a conventional 3-phase 2-level VSI is depicted in Fig. 8. Switching model of the inverter can be represented as in (25)

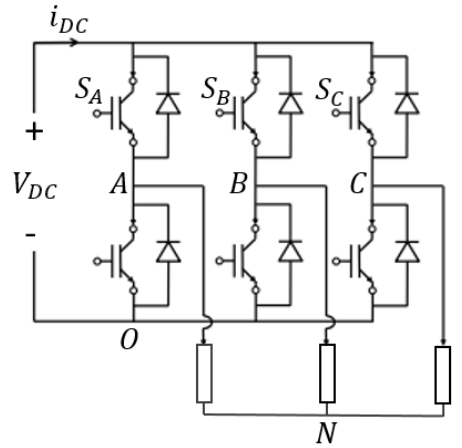

Fig. 8. Layout of 3-phase 2-level VSI.

$$
\left[\begin{array}{c}
\mathrm{V}_{\mathrm{AO}} \\
\mathrm{V}_{\mathrm{BO}} \\
\mathrm{V}_{\mathrm{CO}}
\end{array}\right]=\left[\begin{array}{ccc}
\mathrm{S}_{\mathrm{A}} & 0 & 0 \\
0 & \mathrm{~S}_{\mathrm{B}} & 0 \\
0 & 0 & \mathrm{~S}_{\mathrm{C}}
\end{array}\right]\left[\begin{array}{c}
\mathrm{V}_{\mathrm{DC}} \\
\mathrm{V}_{\mathrm{DC}} \\
\mathrm{V}_{\mathrm{DC}}
\end{array}\right]
$$

where $S_{i}$ is switching function defined as

$$
S_{i}=\left\{\begin{array}{l}
1 \text {, upper switch of leg } i \text { is closed } \\
0, \text { bottom switch of leg } i \text { is closed }
\end{array}, i \in\{A, B, C\}\right.
$$

Phase voltages, $\mathrm{V}_{\mathrm{iN}}$, are defined as difference between leg midpoint and neutral point potentials

$$
\left[\begin{array}{c}
\mathrm{V}_{\mathrm{AN}} \\
\mathrm{V}_{\mathrm{BN}} \\
\mathrm{V}_{\mathrm{CN}}
\end{array}\right]=\left[\begin{array}{c}
\mathrm{V}_{\mathrm{AO}}-\mathrm{V}_{\mathrm{NO}} \\
\mathrm{V}_{\mathrm{BO}}-\mathrm{V}_{\mathrm{NO}} \\
\mathrm{V}_{\mathrm{CO}}-\mathrm{V}_{\mathrm{NO}}
\end{array}\right], \mathrm{V}_{\mathrm{NO}}=\frac{\mathrm{V}_{\mathrm{AO}}+\mathrm{V}_{\mathrm{BO}}+\mathrm{V}_{\mathrm{CO}}}{3}
$$

Alternatively, they can be written as

$$
\left\{\begin{array}{l}
\mathrm{V}_{\mathrm{AN}}=\frac{2 \mathrm{~S}_{\mathrm{A}}-\mathrm{S}_{\mathrm{B}}-\mathrm{S}_{\mathrm{C}}}{3} \mathrm{~V}_{\mathrm{DC}} \\
\mathrm{V}_{\mathrm{BN}}=\frac{-\mathrm{S}_{\mathrm{A}}+2 \mathrm{~S}_{\mathrm{B}}-\mathrm{S}_{\mathrm{C}}}{3} \mathrm{~V}_{\mathrm{DC}} \\
\mathrm{V}_{\mathrm{CN}}=\frac{-\mathrm{S}_{\mathrm{A}}-\mathrm{S}_{\mathrm{B}}+2 \mathrm{~S}_{\mathrm{C}}}{3} \mathrm{~V}_{\mathrm{DC}}
\end{array}\right.
$$

As already mentioned, in order to have lower computational burden, inverters' equations will first be averaged over one switching period $\mathrm{T}_{\mathrm{sw}}$ using operator (28). More details about the procedure can be found in [19].

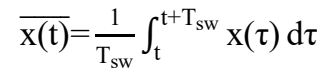

It can be shown that averaged switch functions in sine PWM modulation are

$$
\overline{\mathrm{S}_{\mathrm{i}}}=\frac{1}{2}\left(1+\mathrm{m}_{\mathrm{i}}^{*}\right)
$$

where $\mathrm{m}_{\mathrm{i}}^{*}$ is the modulating signal of the $\mathrm{i}^{\text {th }}$ phase. Thus, applying averaging operator to (27) gives averaged VSI equations $\overline{\mathrm{V}_{\mathrm{iN}}}=\overline{\mathrm{d}_{\mathrm{i}}} \mathrm{V}_{\mathrm{DC}}, \mathrm{i} \in\{\mathrm{A}, \mathrm{B}, \mathrm{C}\}$, in which

$$
\left\{\begin{array}{l}
\overline{\mathrm{d}_{\mathrm{A}}}=\frac{2 \overline{\mathrm{S}_{\mathrm{A}}}-\overline{\mathrm{S}_{\mathrm{B}}}-\overline{\mathrm{S}_{\mathrm{C}}}}{3} \\
\overline{\mathrm{d}_{\mathrm{B}}}=\frac{-\overline{\mathrm{S}_{\mathrm{A}}}+2 \overline{\mathrm{S}_{\mathrm{B}}}-\overline{\mathrm{S}_{\mathrm{C}}}}{\overline{\mathrm{d}_{\mathrm{C}}}}=\frac{-\overline{\mathrm{S}_{\mathrm{A}}}-\overline{\mathrm{S}_{\mathrm{B}}}+2 \overline{\mathrm{S}_{\mathrm{C}}}}{3}
\end{array}\right.
$$

In order to connect VSI model to the already developed $d q$ model of the machine, (30) is also transferred to $d q$ reference frame using $\underline{\underline{K}}$ yielding (31). The process of obtaining $d q$ duty cycles is shown in Fig. 9 (a).

$$
\left[\begin{array}{c}
\mathrm{V}_{\mathrm{q}, \mathrm{s} 1} \\
\mathrm{~V}_{\mathrm{d}, \mathrm{s} 1} \\
\mathrm{~V}_{\mathrm{q}, \mathrm{s} 2} \\
\mathrm{~V}_{\mathrm{d}, \mathrm{s} 2}
\end{array}\right]=\left[\begin{array}{c}
\mathrm{d}_{\mathrm{q}, \mathrm{s} 1} \\
\mathrm{~d}_{\mathrm{d}, \mathrm{s} 1} \\
\mathrm{~d}_{\mathrm{q}, \mathrm{s} 2} \\
\mathrm{~d}_{\mathrm{d}, \mathrm{s} 2}
\end{array}\right] \mathrm{V}_{\mathrm{DC}}
$$

To accomplish the VSI model, DC link current should also be modelled. It can be found by balancing power extracted from the DC link and power absorbed by the inverter as in (32). Averaged $d q$ models of the VSIs are shown in Fig. 9 (b).

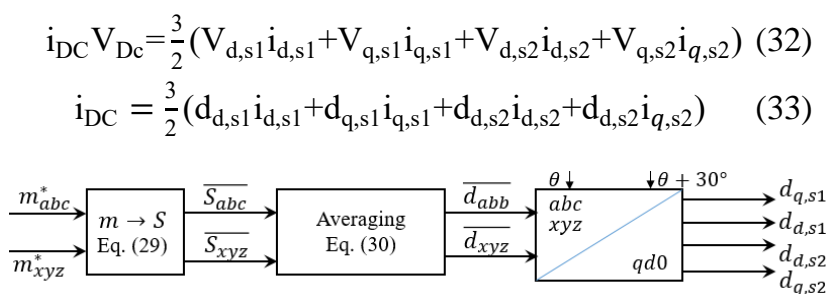

(a)
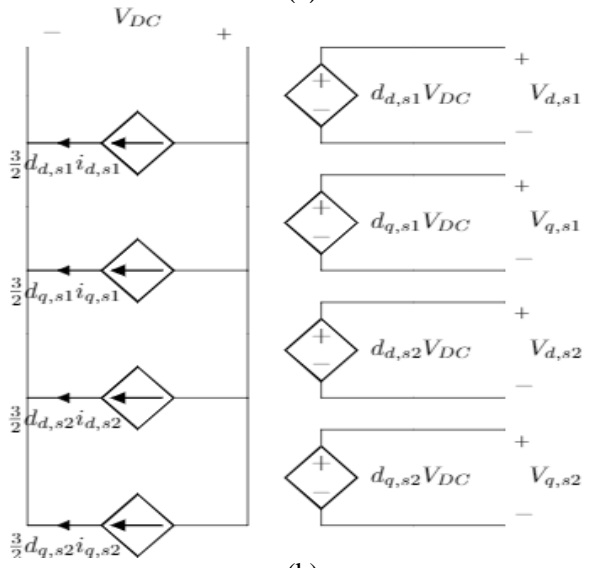

(b)

Fig. 9. (a) $d q$ duty cycles calculation process (b) Averaged model of the two VSI inverters in $d q$ frame

\section{Aircraft Dynamics}

In order to complete the modelling process of the ET system and to properly assess its performance, an aircraft and its ground dynamics model has to be accounted. This allows to evaluate the energy and power requirements of ET for various speed duty cycles for any airport conditions. A simple longitudinal dynamics model can be used to accurately describe ground movement of the aircraft by balancing forces acting in the direction of the motion, which are namely traction force $\left(\mathrm{F}_{\text {traction }}\right)$ and total load force $\left(\mathrm{F}_{\text {load }}\right)(34)$. The ET drive units should be able to provide enough traction force to the wheels in order to overcome total load force (35) that is comprised of

- The road force $\left(\mathrm{F}_{\text {road }}\right)$ that opposes the movement of the aircraft

- Inertial force $\left(\mathrm{F}_{\text {in }}\right)$ that opposes the movement only during acceleration of the aircraft 
$F_{\text {road }}$ is the sum of the rolling resistance $\left(F_{\text {rr }}\right)$, grade of the taxiway resistance $\left(\mathrm{F}_{\text {grade }}\right)$, aerodynamic drag $\left(\mathrm{F}_{\text {aero }}\right)$,

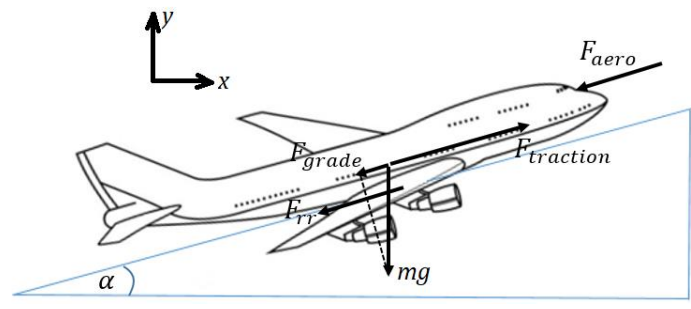

Fig. 10. Road forces acting on the aircraft.

which are all depicted in Fig. 10.

$$
\begin{gathered}
\mathrm{F}_{\text {traction }}=\mathrm{F}_{\text {load }} \\
\mathrm{F}_{\text {load }}=\underbrace{\underbrace{\mathrm{cmg} \cos \alpha}_{\mathrm{F}_{\text {rr }}}+\underbrace{\mathrm{mg} \sin \alpha}_{\mathrm{F}_{\text {grade }}}+\underbrace{\frac{1}{2} \rho \mathrm{c}_{\mathrm{v}} \mathrm{Av}}_{\mathrm{F}_{\text {aero }}}}_{\mathrm{F}_{\text {road }}}+\underbrace{\mathrm{m \frac { \textrm {dv } } { \mathrm { dt } }}}_{\mathrm{F}_{\text {in }}}
\end{gathered}
$$

In (34), $c_{r r}$ is the rolling resistance coefficient, $\mathrm{m}$ is the mass of the aircraft, $g$ is the gravitational constant $\left(9.81 \mathrm{~m} / \mathrm{s}^{2}\right)$, $\alpha$ is the angle of the taxiway slope, $\rho$ is the air density $\left(1.1225 \mathrm{~kg} / \mathrm{m}^{3}\right), \mathrm{c}_{\mathrm{v}}$ is the drag polar coefficient, $\mathrm{A}$ is the equivalent wing area and $\mathrm{v}$ is the aircraft's speed.

Mechanical dynamic equation of one TM is

$$
\mathrm{J}_{\mathrm{m}} \frac{\mathrm{d} \omega_{\mathrm{m}}}{\mathrm{dt}}=\mathrm{T}_{\mathrm{em}}-\frac{1}{\mathrm{n}_{\mathrm{m}}} \mathrm{rF}_{\text {load }}
$$

where $\mathrm{J}_{\mathrm{m}}$ is the inertia of the motor and wheel, $\mathrm{r}$ is the radius of the MLG tyre, $T_{e m}$ is developed electromagnetic torque, $\omega_{\mathrm{m}}$ is the motor's mechanical angular speed and $n_{m}$ number of total installed traction motor. Considering that losses in mechanical drivetrain are negligible, i.e $\mathrm{T}_{\mathrm{em}}=\mathrm{T}_{\text {traction }}$, and that aircraft's linear speed is $v=\omega_{\mathrm{m}} \mathrm{r}$, by substituting (35) in (36), aircraft dynamic equation as seen from the motor's referential i.e. motor's shaft is

$$
\begin{aligned}
\mathrm{J}_{\mathrm{t}} \frac{\mathrm{d} \omega_{\mathrm{m}}}{\mathrm{dt}} & =\mathrm{T}_{\text {traction }}-\frac{1}{\mathrm{n}_{\mathrm{m}}} \mathrm{rF}_{\text {road }} \\
\mathrm{J}_{\mathrm{t}} & =\mathrm{J}_{\mathrm{m}}+\frac{1}{\mathrm{n}_{\mathrm{m}}} \mathrm{mr}^{2}
\end{aligned}
$$

where $\frac{1}{\mathrm{n}_{\mathrm{m}}} \mathrm{mr}^{2}$ represents reflected aircraft body inertia seen from one motor's shaft. The block diagram of the aircraft dynamics model is shown in Fig. 11.

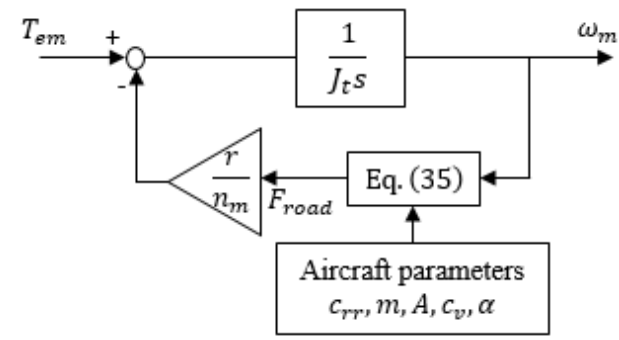

Fig. 11. Block diagram of aircraft dvnamics.

\section{Control}

Block diagram of the whole ET system is presented in Fig. 12. It can be noticed that decoupling block is used as well as $3^{\text {rd }}$ harmonic injection. It is worth mentioning that control is achieved assuming both stars equally contributing to the torque and power production. In other words, the required torque is evenly shared between the two winding sets of the TM (i.e. active-active mode) [20]. Thus, considering that $\mathrm{i}_{\mathrm{q}, \mathrm{s} 1}=\mathrm{i}_{\mathrm{q}, \mathrm{s} 2}$, a classical MTPA strategy of PMSM is used. Finally, the TM is subject to limits and through control method maximum power and torque are limited to $50 \mathrm{~kW}$ and $7 \mathrm{Nm}$ respectively.

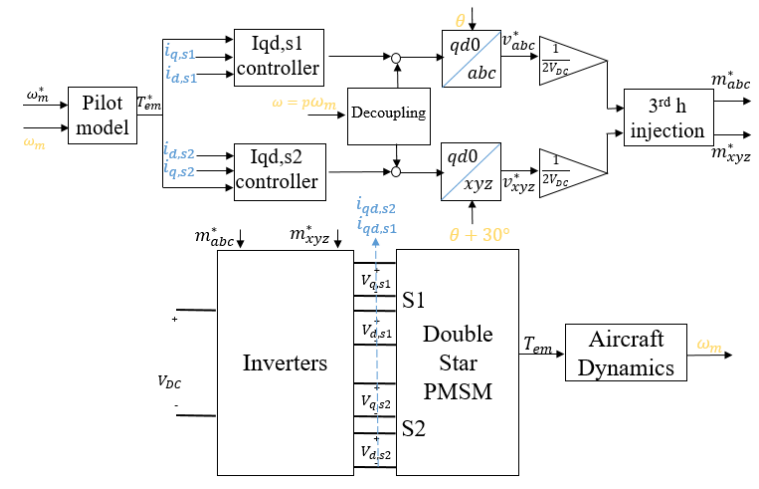

Fig. 12. Block diagram of the complete ET system.

\section{CASE STUDY}

In this section, an actual taxiing mission profile is analysed having as benchmark the B737-400 aircraft. Its parameters are listed in Table I. The taxiing mission is divided into taxi-out part, which happens prior to the take-off, and taxi-in which occurs after the landing. The reference speed profiles of these two driving cycles are reported in Fig. 13 and 14. It can be noticed that the actual speed is not the same as reference speed since forward-facing method is used. Additionally, it provides insight into the vehicle model drivability, and it captures the limits of the physical system [14]. Indeed, due to the imposed limitations on power and torque, the aircraft achieves a limited acceleration and deceleration. For instance, it takes 60 s to reach 20knots from standstill, and this is well below the 90s maximum acceleration time specified in [6]. Similar conclusions can be derived for braking events. For this reason, the aircraft cannot develop the required braking force only by using electric braking. As the braking process has significantly more importance for the aircraft safety, mechanical carbon disk brakes should be used in conjunction with regenerative braking.
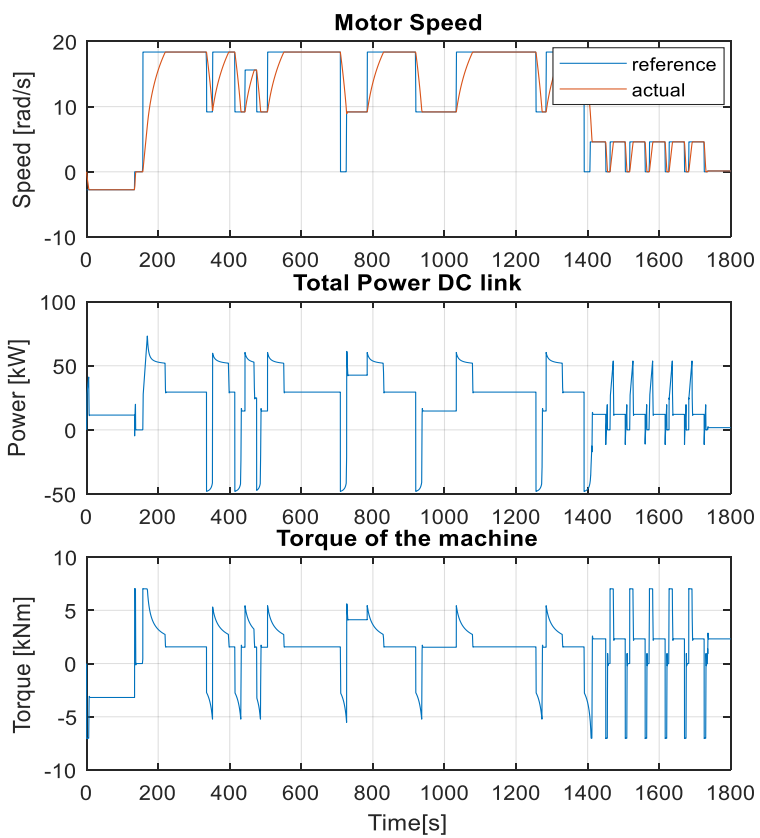

Fig. 13. Taxi-out of B737-400. 
TABLE I. SIMULATED AIRCRAFT MODEL PARAMETERS

\begin{tabular}{|c|c|}
\hline Parameter & Value \\
\hline $\mathrm{m}[\mathrm{t}]$ & $69[21]$ \\
\hline$c_{r r}$ & $0.09[22]$ \\
\hline$A\left[\mathrm{~m}^{2}\right]$ & $105.4[21]$ \\
\hline$c_{v}$ & $0.023[23]$ \\
\hline $\mathrm{r}[\mathrm{m}]$ & $0.535[21]$ \\
\hline
\end{tabular}
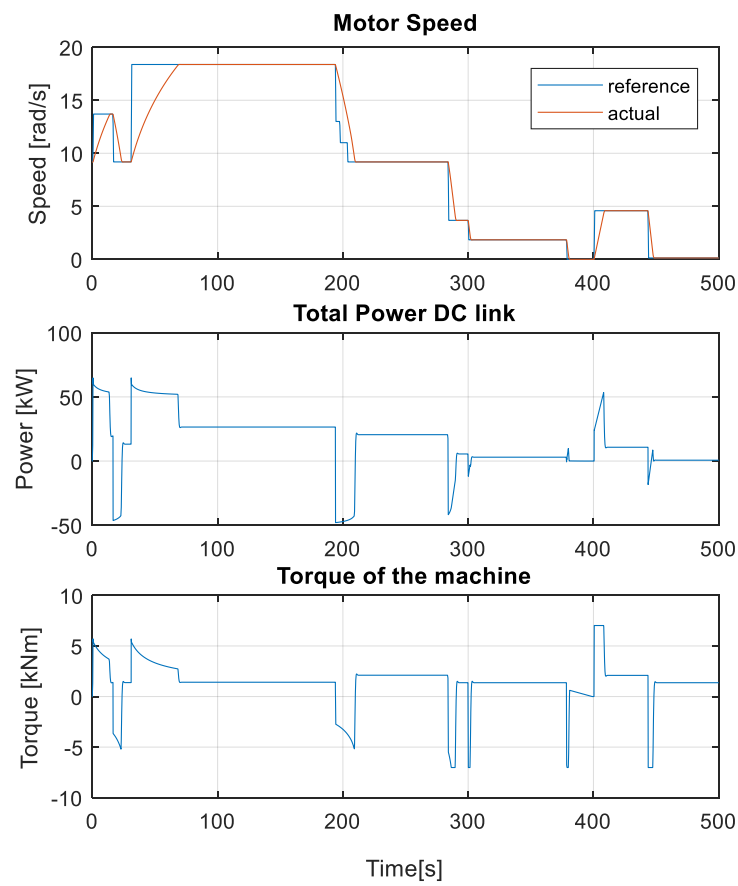

Fig. 14. Taxi-in of B737-400,

Fig. 13 and 14 show also total electric power as seen in the DC link of the converters. From the power profiles, the electric energy requirements can be obtained. During the $1800 \mathrm{sec}$ of taxi-out, one ET drive unit consumed $11.34 \mathrm{kWh}$ of energy, while it is estimated that $1.5 \mathrm{kWh}$ can potentially be regenerated $(13.2 \%)$. On the other hand, during the 500 s of taxi-in, $2.1 \mathrm{kWh}$ is consumed with the potential of recovering $0.35 \mathrm{kWh}(17 \%)$. Additional information that is important for the LESD design is also found, such as the maximum power during regeneration $(51.2 \mathrm{~kW})$, and the duration of the longest braking event (approx. 30s) which may be used in the design of the energy storage subsystem.

\section{CONCLUSIONS}

This paper presented a detailed model for on-board ET system aiming at investigating its performance such as acceleration and regeneration capability, power and energy levels required. The modelled ET system consists of two drive units, one installed in each MLG employing a 6-phase PMSM that is powered from two separate 3-phase inverters. Due to the considered simulation period, i.e. up to $30 \mathrm{~min}$ for a typical taxiing cycle, the ET model was made as simple as possible, in order to achieve fast computational times. Hence, machine and inverters were built in $d q$ reference frame. The ET system versatility was achieved by modeling the aircraft dynamics, which allows to simulate different airport scenarios and aircraft models. Finally, the effectiveness of the developed model was proven through a case study including two taxiing mission profiles (i.e. taxi-out and taxi-in). The developed model will be employed in further studies, in order to propose a holistic method to the selection of LESD for traction applications working on highly irregular duty cycles.

\section{REFERENCES}

[1] P. Giangrande et al., "Considerations on the development of an electric drive for a secondary flight control electromechanical actuator," Press IEEE Trans. Ind. Appl. DOI 10.1109/TIA.2019.2907231, pp. 1-1, 2019.

[2] ICAO, Annex 14, Volume I, Aerodrome Design and Operations, vol. I, no. July. 2018.

[3] M. Lukic et al., "State of the Art of Electric Taxiing Systems," 2018 Int. Conf. Electr. Syst. Aircraft, Railw. Sh. Propuls. Road Veh. Int. Transp. Electrif. Conf., 2018.

[4] European Comission, "Flightpath 2050, Europe's Vision for Aviation." [Online]. Available: https://ec.europa.eu/transport/sites/transport/files/modes/air/doc/flightp ath2050.pdf [Accessed: 16 - May - 2018].

[5] L. Khammash, L. Mantecchini, and V. Reis, "Micro-simulation of airport taxiing procedures to improve operation sustainability: Application of semi-robotic towing tractor," 5th IEEE Int. Conf. Model. Technol. Intell. Transp. Syst. MT-ITS 2017 - Proc., pp. 616-621, 2017.

[6] "EGTS." [Online]. Available: https://www.arts-etmetiers.asso.fr/manifestation_cr/678_compte_rendu.pdf [Accessed: 16 - May - 2018].

[7] "WheelTug Webinar: Cheaper, Safer, and More Comfortable - You Can Have All Three!" [Online]. Available: https://www.youtube.com/watch?v=2eeAMtbJuU8. [Ass: 02-Jul-2018].

[8] B. Sarlioglu and C. T. Morris, "More Electric Aircraft: Review, Challenges, and Opportunities for Commercial Transport Aircraft," IEEE Trans. Transp. Electrif., vol. 1, no. 1, pp. 54-64, 2015.

[9] S. V. Bozhko, C. I. Hill, P. Giangrande, and C. Gerada, "A Novel MultiLevel Electro-Mechanical Actuator Virtual Testing and Analysis Tool," pp. 0249-0249, 2014.

[10] T. Raminosoa, T. Hamiti, M. Galea, and C. Gerada, "Feasibility and electromagnetic design of direct drive wheel actuator for green taxiing," IEEE Energy Convers. Congr. Expo. Energy Convers. Innov. a Clean Energy Futur. ECCE 2011, Proc., pp. 2798-2804, 2011.

[11] Z. Xu et al., "Thermal management of a permanent magnet motor for an directly coupled pump," Proc. - 2016 22nd Int. Conf. Electr. Mach. ICEM 2016, pp. 2738-2744, 2016.

[12] D. Golovanov, M. Galea, and C. Gerada, "High specific torque motor for propulsion system of aircraft," 2016 Int. Conf. Electr. Syst. Aircraft, Railw. Sh. Propuls. Road Veh. Int. Transp. Electrif. Conf. ESARS-ITEC

[13] D. W. Gao, C. Mi, and A. Emadi, "Modeling and Simulation of Electric and Hybrid Vehicles," Proc. IEEE, vol. 95, no. 4, pp. 729-745, 2007.

[14] F. Assadian, G. Mohan, and S. Longo, "Comparative analysis of forward-facing models vs backward-facing models in powertrain component sizing," vol. 2013, no. November, p. 10.7-10.7, 2013.

[15] Z. Mihailovic, H. V Prasad, and D. Borojevic, "Computer Modeling and Analysis of VSI Fed Permanent Magnet Synchronous Motor Drive Systems," pp. 728-735, 1997.

[16] Y. Hu, Z. Q. Zhu, and M. Odavic, "Comparison of Two-Individual Current Control and Vector Space Decomposition Control for Dual," IEEE Trans. Ind. Appl., vol. 53, no. 5, pp. 4483-4492, 2017.

[17] J. Karttunen, S. Kallio, P. Peltoniemi, P. Silventoinen, and O. Pyrhönen, "Dual Three-Phase Permanent Magnet Synchronous Machine Supplied by Two Independent Voltage Source Inverters," in International Symposium on Power Electronics Power Electronics, Electrical Drives, Automation and Motion, 2012, pp. 741-747.

[18] K. Paul, W. Oleg, and Sudhoff Scott, Analysis of Electric Machinery and Drive Systems. 2002.

[19] S. Hiti, D. Boroyevich, and C. Cuadros, "Small-signal modeling and control of three-phase PWM converters," in Proceedings of 1994 IEEE Industry Applications Society Annual Meeting, 1994.

[20] P. Giangrande et al., "Design of PMSM for EMA Employed in Secondary Flight Control Systems,” 2018 IEEE Int. Conf. Electr. Syst. Aircraft, Railw. Sh. Propuls. Road Veh. Int. Transp. Electrif. Conf. ESARS-ITEC 2018, pp. 1-6, 2019.

[21] "Boeing 737-400 Specs." [Online]. Available: https://www.rocketroute.com/aircraft/boeing-737-400. [19-May-2019].

[22] O. Grigore-müler and M. Barbelian, "Regenerative braking for aircraft landing roll phase using an electric machine," 13th Int. Conf. Optim. Electr. Electron. Equip., pp. 584-593.

[23] J. Sun, J. M. Hoekstra, and J. Ellerbroek, "Aircraft Drag Polar Estimation Based on a Stochastic Hierarchical Model," in SESAR Innovation Days, 2018 